\title{
Optical Nonlinear Properties of Gold Nanoparticles Synthesized by Laser Ablation in Polymer Solution
}

\author{
M. Tajdidzadeh, ${ }^{1}$ A. B. Zakaria, ${ }^{1,2}$ Z. Abidin Talib, ${ }^{1}$ A. S. Gene, ${ }^{3}$ and S. Shirzadi ${ }^{4}$ \\ ${ }^{1}$ Department of Physics, Faculty of Science, Universiti Putra Malaysia, 43400 UPM Serdang, Selangor, Malaysia \\ ${ }^{2}$ Materials Synthesis and Characterization Laboratory, Advanced Institute of Technology, Universiti Putra Malaysia, \\ 43400 UPM Serdang, Selangor, Malaysia \\ ${ }^{3}$ Department of Physics, Faculty of Natural Sciences, Ibrahim Badamasi Babangida University, Lapai 234066, Nigeria \\ ${ }^{4}$ Department of Physics, Faculty of Science, Islamic Azad University Branch of Science and Research, Tehran, Iran
}

Correspondence should be addressed to A. B. Zakaria; azmizak@gmail.com

Received 4 November 2016; Revised 16 January 2017; Accepted 24 January 2017; Published 22 February 2017

Academic Editor: Giuseppe Compagnini

Copyright (C) 2017 M. Tajdidzadeh et al. This is an open access article distributed under the Creative Commons Attribution License, which permits unrestricted use, distribution, and reproduction in any medium, provided the original work is properly cited.

In the present study, gold nanoparticles were synthesized in various polymer solutions by means of employing laser ablation technique at the same ablation time. Specifically, gold nanoparticles were synthesized in polyethylene glycol and chitosan solutions, in order to compare the effects of the liquid media which served as stabilizers for particle size and volume fraction of nanoparticles. In addition, this experiment was repeated in distilled water for reference purposes. As the findings indicated, the particle size which was obtained in polyethylene glycol was about $7.49 \mathrm{~nm}$, that is, smaller than those of chitosan solution and distilled water, respectively. In contrast, it was observed that the volume fraction of gold nanoparticles increased in polyethylene glycol in comparison with the other media which indicated an effect on the formation of NPs. On the other hand, $Z$-scan technique was employed to measure the nonlinear refractive index and nonlinear absorption coefficient of nanofluids containing gold nanoparticles. Consequently, the nonlinear properties of nanofluids pointed to a significant contribution with the number of nanoparticles observed in fluids and both optical nonlinear parameters were observed to increase by means of a prior increase in the volume fraction of Au-NPs in polyethylene glycol solution.

\section{Introduction}

A shift from the existing chemical methods into Laser ablation in liquid phase (LALP) to synthesize nanoparticles (NPs) has over the years been observed owing mainly to its environmental-friendliness, contamination-free, and nonhazardous. Among various NPs which are widely available, gold nanoparticles (Au-NPs) drew particular attention among scholars owing to its wide range of applications such as sensors [1], electronics [2], medical diagnoses [3], and therapeutic agent delivery [4]. In this regard, it has to be noted that the response of the NPs to the interaction of light is dependent on the size of the particles [5]. A review of related literature clearly indicates variations observed in methods employed to prepare Au-NPs, for instance, the chemical methods $[6,7]$, sonochemical $[8]$, microwave technique [9], Green synthesis of Au-NPs using plane leaf extract [10], organic solvents [11], nonorganic solvents [12], graphene oxide [13] by means of LALP, and ion implantation [14]. Moreover, Au-NPs are very interesting when they are deposited on the ITO substrates [15], for instance, particular interest for the photoinduced nonlinear optics determined by interfaces between the conductivity of electrodes and the charge density distribution [16].

It has been reported that nonlinear optical properties of Au-NPs by means of electron beam deposition have been studied by employing $Z$-scan technique [17]. It is worth highlighting that $Z$-scan technique is a simple and accurate technique which can be useful in determining the nonlinear (NL) properties. It can also be observed that, in this technique, the laser beam goes through the focal point of the beam from NL medium and changes in its transmittance, which in turn may cause the nonlinear refractive (NLR) and nonlinear absorption (NLA) which are measured by both the close 




(a)

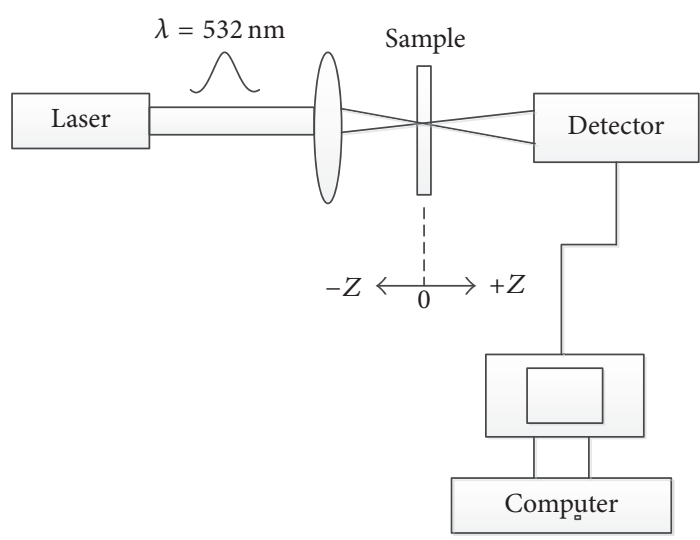

(b)

FIGURE 1: Schematic diagrams of (a) laser ablation set-up and (b) $Z$-scan set-up.

aperture and open aperture, respectively. The NLR index of high NL aggregate film which is based on self-assemble $\mathrm{Au}-\mathrm{NPs}$ is reportedly measured by $Z$-scan technique [18]. Moreover, the NLR index of the colloidal Au-NPs under the continuous wave illumination is reportedly investigated by means of employing the $z$-scan technique [19].

As in the case of the present study, the focus was on looking into synthesizing the Au-NPs in polyethylene glycol [20] and chitosan [21] solutions by employing LALP technique in order to measure the effect of liquid media on both the size and formation of NPs. The LALP is considered as a green method in comparison with chemical method that has been used to synthesize gold nanoparticle. Moreover, the novelty of present study is using polymer solution instead of distilled water to decrease the size of Au-NPs. The focus then shifted to investigating the effect on optical NL properties of nanofluids containing Au-NPs. The samples which were prepared for the present study featured a UV-Vis spectrometer (UV-1650 PC, Shimadzu) with $1 \mathrm{~cm}$ optical path cell to confirm the Au-NPs peak absorption, transmission electron microscopy (TEM, Hitachi $\mathrm{H}-7100$ ) at $120 \mathrm{kV}$ accelerating voltages for NPs' morphological information, and atomic absorption spectrometer (AAS, S Series) which may serve to measure the mass of Au-NPs in solution. Also, Z-scan technique was used to measure NL optical properties, respectively.

\section{Experimental Details}

2.1. Fabrication of Au-NPs Using Laser Ablation Technique. In order to produce the Au-NP, a gold plate (i.e., Sigma-Aldrich, 99.99\% purity) that was initially washed by means of using ultrasonic bath for an estimated 30 minutes was placed in a cubic cell including a $20 \mathrm{~mL}$ of solution. At this stage, both the chitosan and polyethylene glycol (PEG) solution were used to serve as stabilizers. In this regard, an estimated $2 \mathrm{~g}$ of chitosan and $2 \mathrm{~g}$ of PEG powder were dissolved into $100 \mathrm{~mL}$ of water. The chitosan solution was prepared within an estimated one hour at $60^{\circ} \mathrm{C}$ and preparation PEG solution was also similarly conducted for one hour but at room temperature.
The Q switched Nd:YAG pulse laser (SL400/SL800 system) with $532 \mathrm{~nm}$ wavelength, $10 \mathrm{~Hz}$ repetition rate, and $10 \mathrm{~ns}$ duration, respectively, was used for ablation to produce $\mathrm{Au}$ NPs from the target. The laser output power $35 \mathrm{~mJ} /$ pulse was measured by the optical power detector (Nova II) [22]. The laser beam was focused on the plate by means of using a lens with $25 \mathrm{~cm}$ focal lengths. The ablation was carried out at room temperature for an estimated 15 minutes and, in the course of ablating the solution, it was magnetically stirred to ensure they are well dispersed. Figure 1(a), shows the schematic diagram of laser ablation set-up.

Here, volume fraction was calculated through a simple relationship:

$$
V=\frac{V_{s}}{V_{s}+V_{L}},
$$

where $V_{L}$ is the liquid volume, $V_{s}=m / \rho$ is the volume of $\mathrm{Au}$ particles, $\rho$ is the Au density, and $m$ is the Au particle mass dispersed in solution [23].

2.2. Nonlinear Properties of Au-NPs Using Z-Scan Technique. $Z$-scan set-up in this context was considered to determine the NLR index and the NLA coefficient of nanofluids. The schematic diagram of $Z$-scan experimental set-up is shown in Figure 1(b). It has to be noted that the experiment was conducted at room temperature with a $\mathrm{CW}$ green laser diode working at $532 \mathrm{~nm}$ wavelength (SDL-532-150T). The beam was focused at a small spot using a convex lens with a measurement of $10 \mathrm{~cm}$ in focal length and the sample was then moved along the $z$-axis by microstepping controller (BSC101), run by a Lab View program. The power output of the laser beam at the focal point $(40 \mathrm{~mW})$ was measured by power meter (Newport 193-6). The light transmitted in the far field passed through the aperture (i.e., aperture size $2 \mathrm{~mm}$ ) and the beam intensity was recorded by a silicon photo detector (i.e., Newport 918D-SL-OD3). A quartz optical cell containing the sample solution was moved across the focal area along the direction of $z$-axis to extract the NLR index, and the NLA coefficient was measured in line with the closed aperture and open aperture $Z$-scan experiment. 
2.2.1. Closed Aperture. The NLR index $\left(n_{2}\right)$ can be computed from the fitting of normalized transmittance of the experimental data along with the theoretical transmittance curve of closed aperture in accordance with (2) in the following:

$$
\Delta T(Z, \Delta \varphi)=1-\frac{4 \Delta \varphi_{0} x}{\left(x^{2}+1\right)\left(x^{2}+9\right)},
$$

where $\Delta \varphi_{0}$ is the axis phase change at the focus point, $x=$ $Z / Z_{0}, x$ is a normalized distance on the $z$-axis, and $n_{2}$ is related to phase change $[24,25]$.

$$
n_{2}=\frac{\Delta \varphi_{0}}{k I_{0} L_{\mathrm{eff}}}
$$

where $k$ is a wave vector, $I_{0}$ is the beam intensity at focus point, and $S$ is the aperture linear transmittance. $L_{\text {eff }}$ is the effective thickness of the sample that is obtained by means of the following equation, where $\alpha$ is the linear absorption coefficient and $L$ represents the sample thickness $(1 \mathrm{~mm})$.

$$
L_{\mathrm{eff}}=\frac{(1-\exp (-\alpha L))}{\alpha}
$$

2.2.2. Open Aperture. On the other hand, if the sample saturated absorption is observed as a consequence of increasing incident intensity, the transmission may in turn reach the maximum level in the focal region [26]. In this case, transmitted light is measured by means of a detector in the absence of an aperture and the measured quantity is the normalized transmittance which is provided by the equation in the following [27]:

$$
T=q_{0}^{-1}(z) \ln \left(1+q_{0}(z)\right), \quad\left|q_{0}(z)\right|<1,
$$

where $q_{0}(z)$ is a parameter characterizing the strength of the nonlinearity that for Gaussian beam.

$$
q_{0}(z)=\beta I_{0} L_{\mathrm{eff}},
$$

where $\beta$ is a NLA coefficient that is obtained by fitting the experimental data with theoretical data (see (5)).

\section{Results and Discussion}

3.1. Characterization of Au-NPs. Figure 2 indicates the UVvisible absorption spectra of Au-NPs prepared by LA in PEG, chitosan solution, and distilled water as references, respectively. The estimated peaks of $530-550 \mathrm{~nm}$ for all samples are related to the formation of Au-NPs $[28,29]$. It is obvious that the maximum wavelength indicated a slightly blue shift from $550 \mathrm{~nm}$ to $524 \mathrm{~nm}$ from distilled water to the PEG solution, respectively. Such a shift, according to the Mie theory, is due to the size reduction of particles [30]. Another interesting point from UV-visible spectra is the increasing intensity of surface Plasmon resonance (SPR) observed in various media that clearly indicates that the intensity of SPR in PEG is relatively higher than other media. The intensity of surface plasmon may have a direct relationship with the density of particles contained in solutions. Referring to the

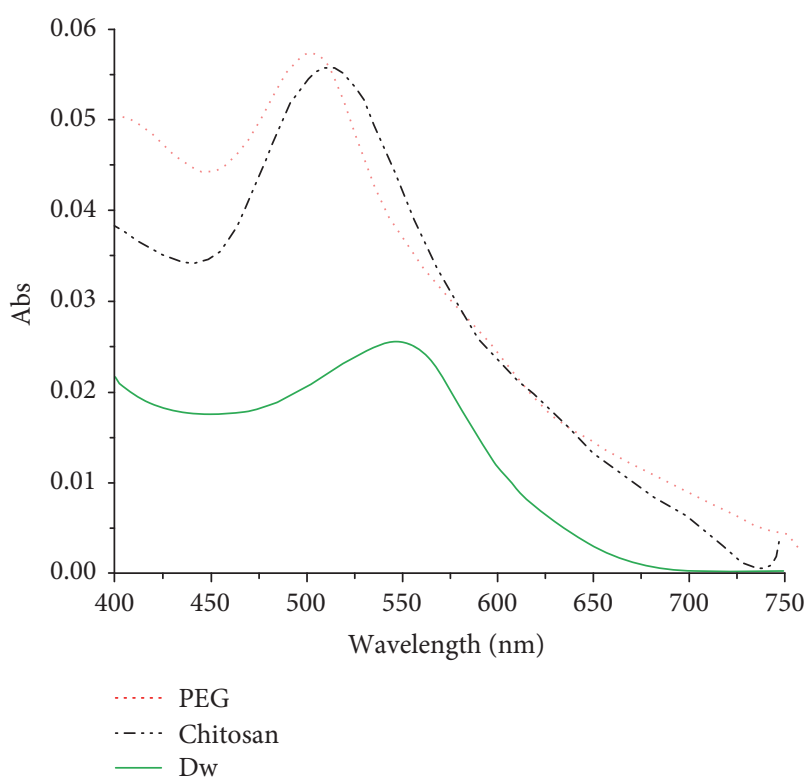

FIgURE 2: UV-visible spectra of Au-NPs in PEG solution, chitosan solution, and distilled water.



FIgURE 3: Volume fraction and absorbance of Au-NPs depend on the media.

scenario, it can be interpreted that the concentration of $\mathrm{Au}-$ NPs in PEG is slightly higher than that of chitosan solution and distilled water as well, which is confirmed by measuring volume fraction (see (1)) of NPs in solutions.

Thus, Figure 3 clearly illustrates that the volume fraction along with the intensity of absorption of Au-NPs in this context is highly dependent on liquid media which were used as stabilizers to synthesize NPs. Nevertheless, it is worth highlighting that both parameters observed significant reduction in distilled water in comparison with the polymer solutions.

The TEM images and mean diameter of particles for synthesized Au-NPs in various polymer solutions and distilled water are demonstrated in Figure 5. The small particle size gained from PEG is largely due to the TEM images. The 
TABLE 1: Mean diameter, standard deviation, and volume fraction of Au-NPs in polymer solution.

\begin{tabular}{lccc}
\hline Media & $\begin{array}{c}\text { Mean diameter } \\
(\mathrm{nm})\end{array}$ & $\begin{array}{c}\text { Standard deviation } \\
(\mathrm{nm})\end{array}$ & $\begin{array}{c}\text { Volume fraction } \\
\times 10^{-7}\end{array}$ \\
\hline PEG & 7.49 & 1.91 & 6.3 \\
Chitosan & 10.33 & 2.42 & 0.58 \\
$\begin{array}{l}\text { Distilled } \\
\text { water }\end{array}$ & 20.76 & 4.83 & 0.25 \\
\hline
\end{tabular}

details of Au-NPs, namely, mean size, standard deviation, and volume fraction in all media are illustrated in Table 1. Moreover, the mean particles size, which is approved by UVvisible spectra is obtained and the blue shift showed that the particles diameter of Au-NPs in PEG were smaller than other media. Moreover, TEM images have also confirmed the approximately spherical shape of Au-NPs in solutions. Another noticeable point in TEM images was the dispersing NPs in solution which indicates that Au-NPs is well dispersed in PEG compared to chitosan solution and water.

Size reduction occurred due to the interaction between the liquid media of NPs after formation. NPs may be absorbed by solution because it is the key players in preventing NPs from agglomeration and growing. The mechanism of capping $\mathrm{Au}-\mathrm{NPs}$ in PEG solution may be explained by hydroxyl groups [31], while, in chitosan solution, it occurred via hydroxyl groups and nitrogen atoms of amine groups [32], which were schematically indicated in Figure 4.

Figure 6 indicated the clear relationship of particle size with volume fraction and the absorbance intensity Au-NPs, which were prepared simultaneously with ablation time. Notably, decreasing the particle sizes in PEG solution yielded an increase in the fraction volume and, consequently, the absorbance intensity also increased due to the high viscosity and density of PEG solution compared to other media.

3.2. Optical Nonlinear Properties. The nonlinear properties of samples, namely, particle size and volume fraction of $\mathrm{Au}-$ NPs, were investigated in polymer solutions. Figure 7 shows the normalized transmittance of closed aperture of $Z$-scan experiment for Au-NPs in PEG and chitosan solutions. The particles' sizes and fractions' volume derived from Au-NPs in both media are itemized in Table 1. Asymmetric curves were observed due to the fact that the theoretical transmittance curves fitted well to the experimental data for samples in liquid phase containing gold NPs. Moreover, the normalized transmittance signal was obtained in accordance with the maximum peak value. It should be noted that the peakvalley shapes of the curves indicated the self-defocusing phenomena of Au-NPs. The results suggested that $n_{2}$ increased more in PEG solution rather than in the chitosan solution. $n_{2}$ Results obtained from (2) were negative, thus, confirming the occurrence of self-defocusing phenomenon [33, 34].

Figure 8 illustrates the NLA asymmetries curves of AuNPs in PEG and chitosan solutions. Asymmetric samples were obtained owing to the laser beam heating, which created waves that passed through the quartz cell with $1 \mathrm{~mm}$ thickness inside the samples $[35,36]$. The NLA coefficient, $\beta$, was
TABLE 2: NLR index and NLA coefficient of Au-NPs in PEG and chitosan solutions.

\begin{tabular}{lccc}
\hline Media & $\Delta \varphi_{0}$ & $\begin{array}{c}n_{2}\left(\mathrm{~cm}^{2} / \mathrm{W}\right) \\
\times 10^{-7}\end{array}$ & $\begin{array}{c}\beta(\mathrm{cm} / \mathrm{W}) \\
\times 10^{-7}\end{array}$ \\
\hline PEG & -0.411 & -8.2 & 1.48 \\
Chitosan & -1.715 & -3.4 & 0.58 \\
\hline
\end{tabular}

obtained from fitting the theoretical normalized transmittance data (see (4)) to the experimental open aperture data [37].

Table 2 indicates the optical nonlinear results of Au-NPs obtained in both media. It should be noted that the increasing volume fraction and decreasing particle size of NPs in PEG solution (i.e., demonstrated in Table 1) were reflected in the NLR index and NLA coefficient of NPs, in which they also increased compared to in chitosan solution. The results of optical NL properties obtained are listed in Table 2.

Thus, the nonlinear properties of nanofluids containing $\mathrm{Au}-\mathrm{NPs}$ noticeably increased by increase of the concentration of NPs in polymer solutions and it depended on the size of Au-NPs as well [13]. Subsequently, Figure 9 presented the relationship of NLR index and NLA coefficient with particle size and volume fraction of Au-NPs in polymer solutions.

\section{Conclusions}

The nonlinear refractive index of gold nanofluid, which was prepared at different particle sizes in various polymer solutions has been successfully measured by means of a single beam $z$-scan method. The measurement was carried out at room temperature using a CW green laser beam at $532 \mathrm{~nm}$ wavelength. Notably, the Au-NPs indicated a good nonlinear response. The sign of the nonlinear refractive index was negative indicating self-defocusing phenomenon and the magnitude was in the order of $10^{-7} \mathrm{~cm}^{2} / \mathrm{W}$. The nonlinear effect increased with the decrease of particles' size in PEG solution at an estimated $7.49 \mathrm{~nm}$. On the other hand, NLA coefficient increased together with the volume fraction's increase of Au-NPs in PEG solution compared to that in the chitosan solution.

\section{Competing Interests}

The authors declare that there is no conflict of interests regarding the publication of this paper.

\section{Authors' Contributions}

The main idea for the experiment was thought up by Mojgan Tajdidzadeh. Experimental work and analysis of the experimental data was performed by Mojgan Tajdidzadeh and S. Shirzadi. The analysis of the experimental data was carried out by Azmi B. Zakaria and Zainal Abidin Talib. Mojgan Tajdidzadeh and Azmi B. Zakaria, A. S. Gene, and S. Shirzadi have participated in writing the manuscript. 


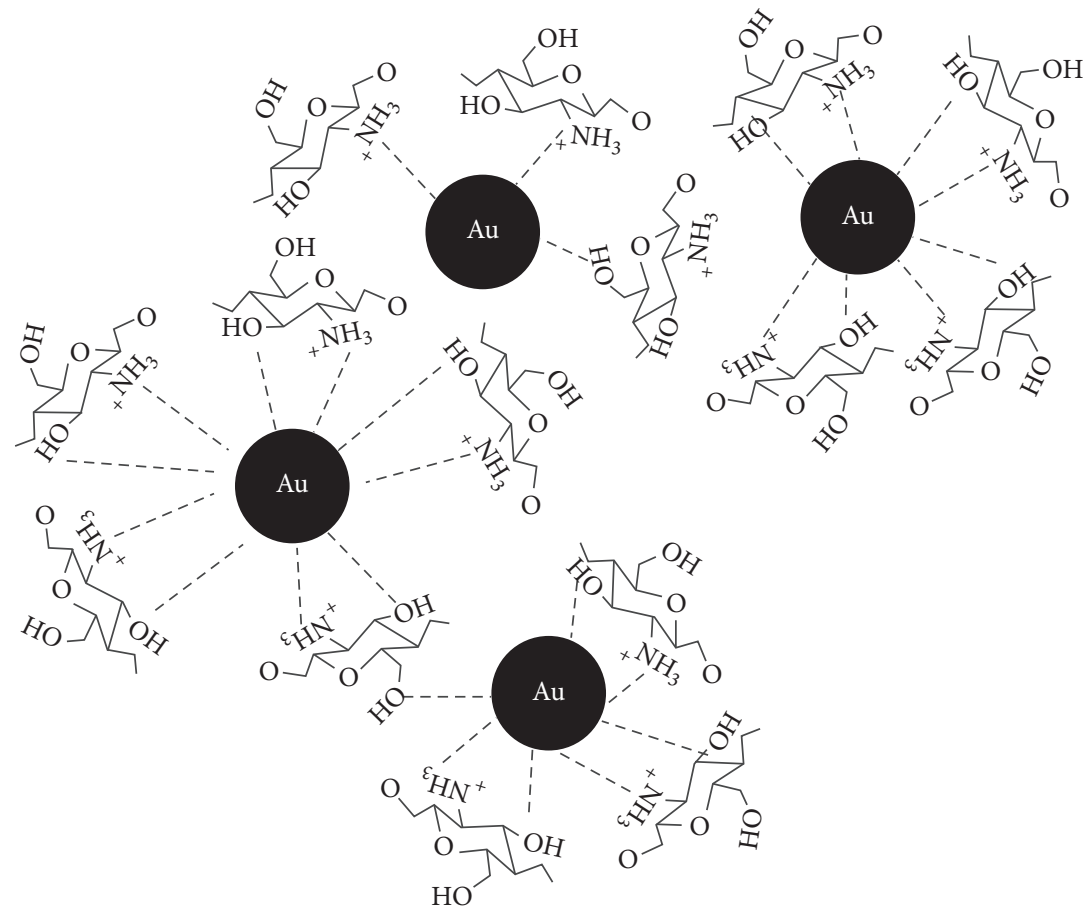

(a)



(b)

FIgure 4: Schematic diagrams of capping Au-NPs: (a) chitosan solution and (b) PEG solution. 



(a)
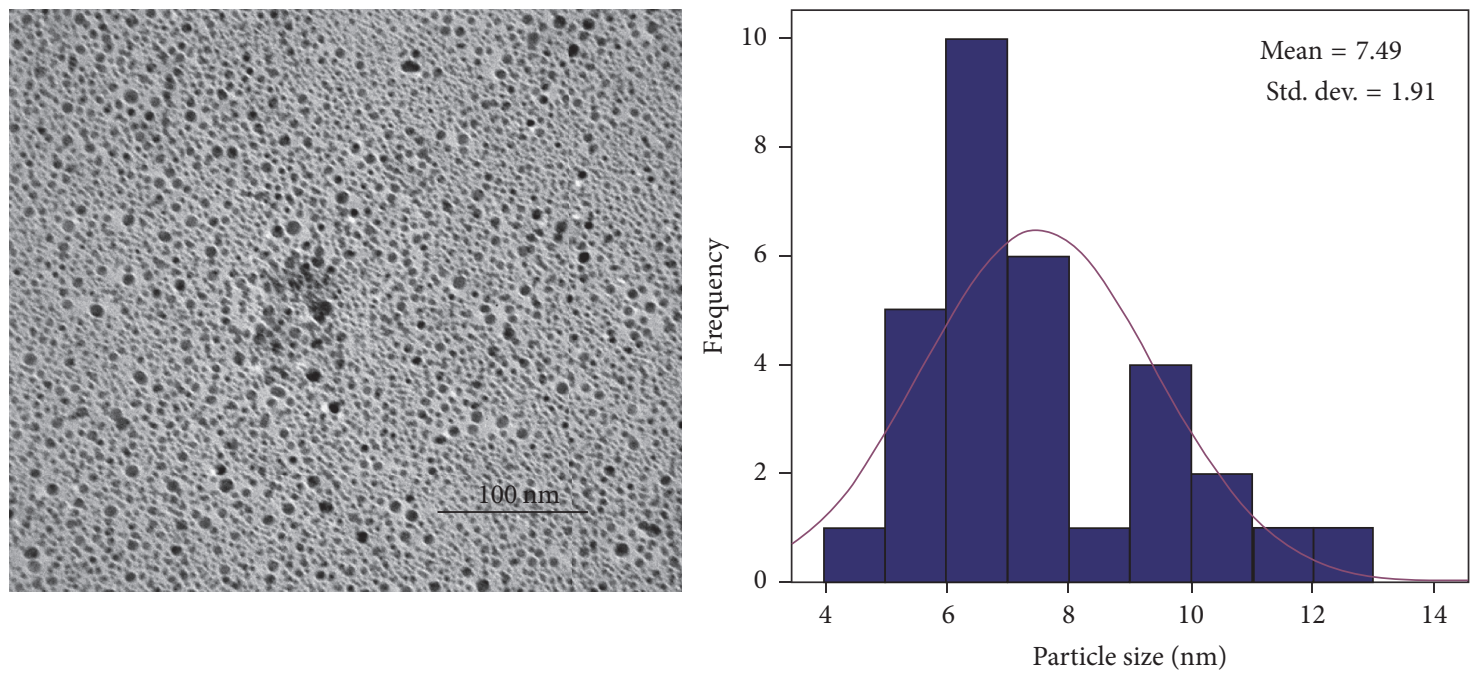

(b)
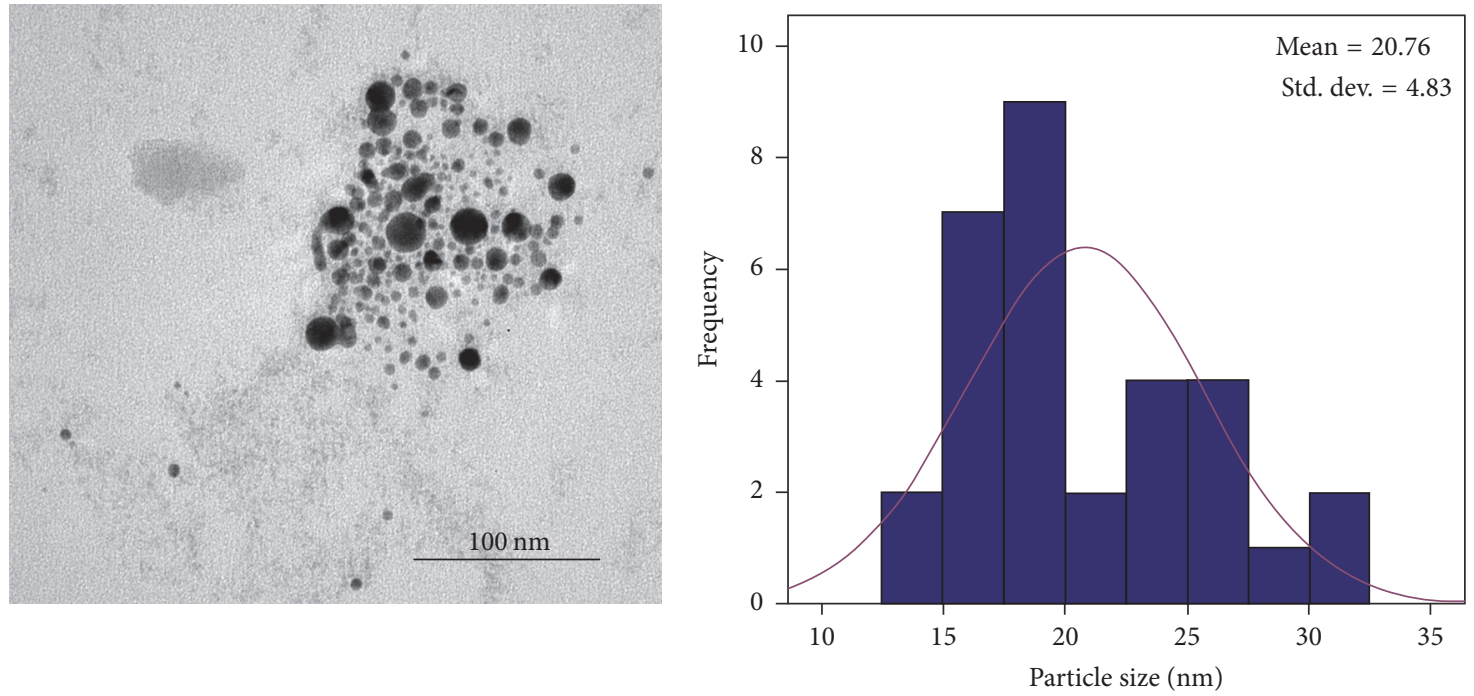

(c)

FIGURE 5: TEM images and their accompanying size distribution of Au-NPs in various media: (a) chitosan, (b) PEG, and (c) distilled water. 


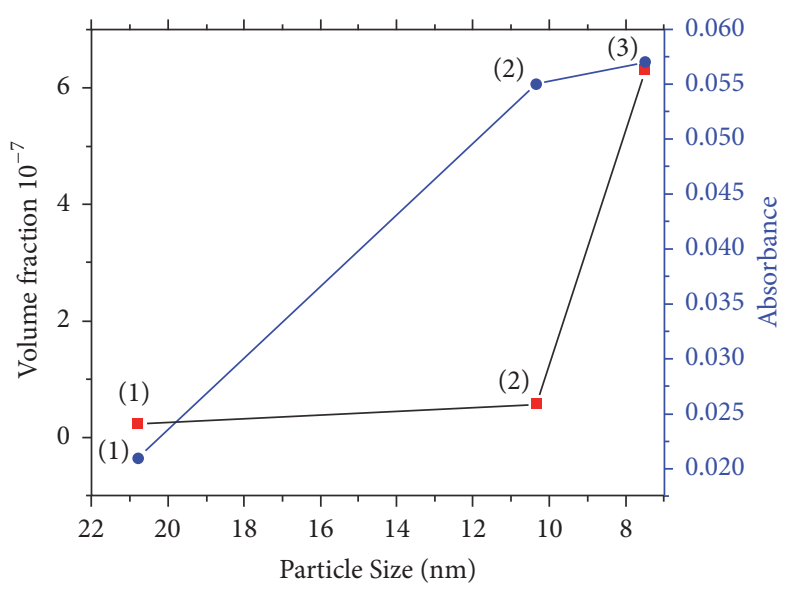

(1) Distilled water
(2) Chitosan
(3) PEG

FIGURE 6: Relationship between volume fractions, particle size, and intensity of absorbance of Au- NPs in polymer solutions and distilled water.



(a)

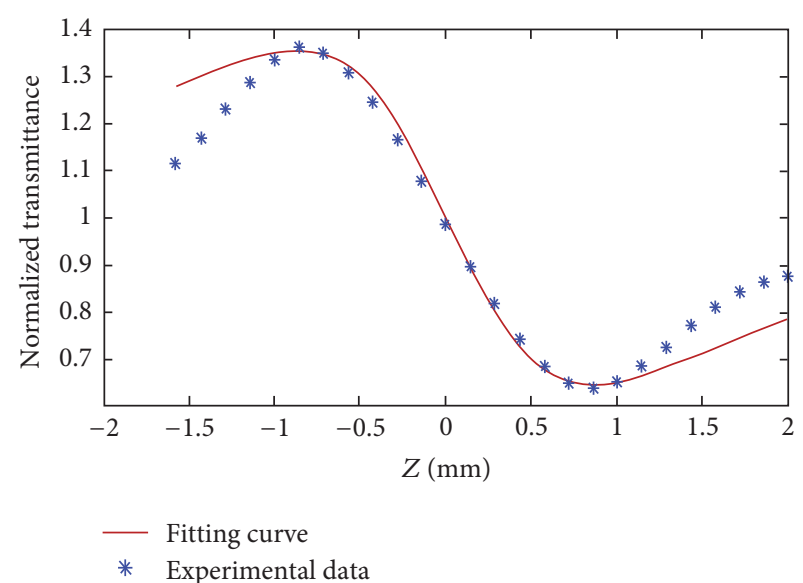

(b)

Figure 7: Normalized transmittance curve of closed aperture Z-scan set-up for Au-NPs (a) chitosan and (b) PEG solution prepared at 15 min ablation time.



(a)



(b)

FIGURE 8: Normalized transmittance curve of open aperture $Z$-scan set-up of Au-NPs in (a) chitosan solution and (b) PEG solution. 


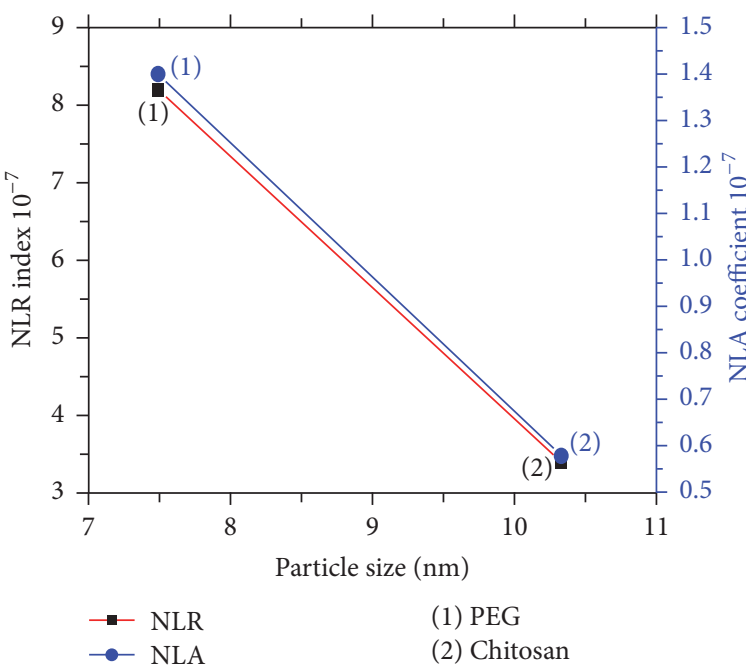

(a)

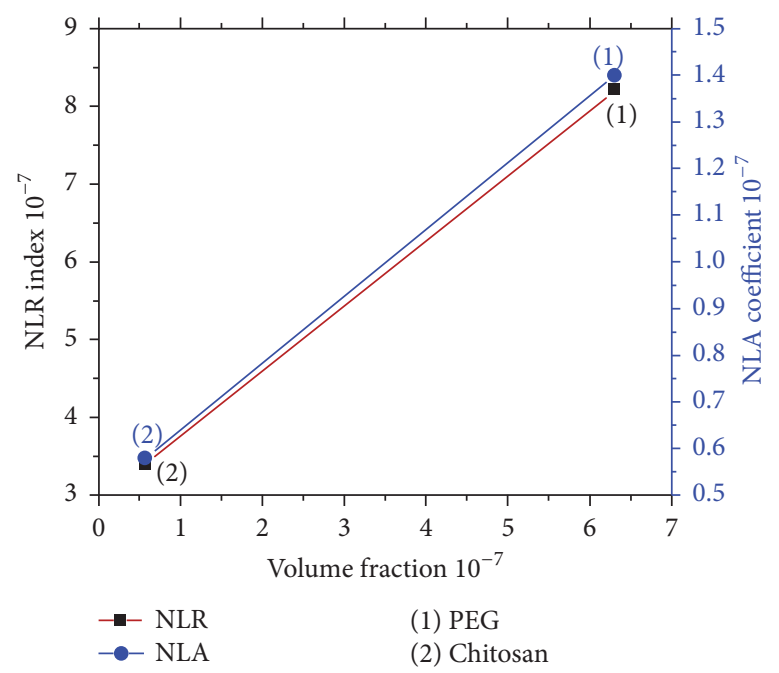

(b)

FIGURE 9: The relationship of NLR index and NLA coefficient with (a) particle size and (b) volume fraction of Au-NPs in polymer solutions.

\section{Acknowledgments}

The authors gratefully acknowledged the financial support for this work from the Fundamental Research Grant Scheme (FRGS) of Project no. 01-02-13-1345FR and IPS Putra Grant of Project no. GP-IPS/2014/9433964.

\section{References}

[1] K. Saha, S. S. Agasti, C. Kim, X. Li, and V. M. Rotello, "Gold nanoparticles in chemical and biological sensing," Chemical Reviews, vol. 112, no. 5, pp. 2739-2779, 2012.

[2] A. Tomar and G. Garg, "Short review on application of gold nanoparticles," Global Journal of Pharmacology, vol. 7, no. 1, pp. 34-38, 2013.

[3] W. Cai, T. Gao, H. Hong, and J. Sun, "Applications of gold nanoparticles in cancer nanotechnology," Nanotechnology, Science and Applications, vol. 1, pp. 17-32, 2008.

[4] L. Vigderman and E. R. Zubarev, "Therapeutic platforms based on gold nanoparticles and their covalent conjugates with drug molecules," Advanced Drug Delivery Reviews, vol. 65, no. 5, pp. 663-676, 2013.

[5] A. C. Templeton, J. J. Pietron, R. W. Murray, and P. Mulvaney, "Solvent refractive index and core charge influences on the surface plasmon absorbance of alkanethiolate monolayerprotected gold clusters," Journal of Physical Chemistry B, vol. 104, no. 3, pp. 564-570, 2000.

[6] M. Faraday, "The bakerian lecture: experimental relations of gold (and other metals) to light," Philosophical Transactions of the Royal Society of London, vol. 147, pp. 145-181, 1857.

[7] J. Turkevich, P. C. Stevenson, and J. Hillier, "A study of the nucleation and growth processes in the synthesis of colloidal gold," Discussions of the Faraday Society, vol. 11, pp. 55-75, 1951.

[8] K. Okitsu, M. Ashokkumar, and F. Grieser, "Sonochemical synthesis of gold nanoparticles: effects of ultrasound frequency," Journal of Physical Chemistry B, vol. 109, no. 44, pp. 2067320675, 2005.

[9] R. Das, P. J. Babu, N. Gogoi, P. Sharma, and U. Bora, "Microwave-mediated rapid synthesis of gold nanoparticles using
Calotropis procera latex and study of optical properties," ISRN Nanomaterials, vol. 2012, Article ID 650759, 6 pages, 2012.

[10] Y. Li, T.-Y. Wu, S.-M. Chen, M. A. Ali, and F. M. A. AlHemaid, "Green synthesis and electrochemical characterizations of gold nanoparticles using leaf extract of Magnolia kobus," International Journal of Electrochemical Science, vol. 7, no. 12, pp. 1274212751, 2012.

[11] V. Amendola, S. Polizzi, and M. Meneghetti, "Laser ablation synthesis of gold nanoparticles in organic solvents," Journal of Physical Chemistry B, vol. 110, no. 14, pp. 7232-7237, 2006.

[12] E. V. Barmina, G. A. Shafeev, P. G. Kuzmin, A. A. Serkov, A. V. Simakin, and N. N. Melnik, "Laser-assisted generation of gold nanoparticles and nanostructures in liquid and their plasmonic luminescence," Applied Physics A: Materials Science and Processing, vol. 115, no. 3, pp. 747-752, 2014.

[13] A. R. Sadrolhosseini, A. S. M. Noor, N. Faraji, A. Kharazmi, and M. A. Mahdi, "Optical nonlinear refractive index of laserablated gold nanoparticles graphene oxide composite," Journal of Nanomaterials, vol. 2014, Article ID 962917, 8 pages, 2014.

[14] W. Husinsky, A. Ajami, P. Nekvindova, B. Svecova, J. Pesicka, and M. Janecek, "Z-scan study of nonlinear absorption of gold nano-particles prepared by ion implantation in various types of silicate glasses," Optics Communications, vol. 285, no. 10-11, pp. 2729-2733, 2012.

[15] K. Ozga, T. Kawaharamura, A. Ali Umar et al., "Second order optical effects in Au nanoparticle-deposited $\mathrm{ZnO}$ nanocrystallite films," Nanotechnology, vol. 19, no. 18, Article ID 185709, 2008.

[16] M. A. Aziz, M. Oyama, K. Ozga et al., "Optical features of the gold nanoparticles deposited on ITO substrates," Optics Communications, vol. 284, no. 1, pp. 245-248, 2011.

[17] M. H. Mezher, A. Nady, R. Penny, W. Y. Chong, and R. Zakaria, "Z-scan studies of the nonlinear optical properties of gold nanoparticles prepared by electron beam deposition," Applied Optics, vol. 54, pp. 9703-9708, 2015.

[18] S. Bai, Q. Li, H. Zhang et al., "Large third-order nonlinear refractive index coefficient based on gold nanoparticle aggregate films," Applied Physics Letters, vol. 107, no. 14, Article ID 141111, 2015. 
[19] A. B. Ortega, M. L. A. Carrasco, M. M. M. Otero et al., "Nonlocal nonlinear refractive index of gold nanoparticles synthesized by ascorbic acid reduction: comparison of fitting models," Journal of Modern Optics, vol. 61, pp. S68-S73, 2014.

[20] J. Manson, D. Kumar, B. J. Meenan, and D. Dixon, "Polyethylene glycol functionalized gold nanoparticles: the influence of capping density on stability in various media," Gold Bulletin, vol. 44, no. 2, pp. 99-105, 2011.

[21] D. R. Bhumkar, H. M. Joshi, M. Sastry, and V. B. Pokharkar, "Chitosan reduced gold nanoparticles as novel carriers for transmucosal delivery of insulin," Pharmaceutical Research, vol. 24, no. 8, pp. 1415-1426, 2007.

[22] H. Imam, K. Elsayed, M. A. Ahmed, and R. Ramdan, "Effect of experimental parameters on the fabrication of gold nanoparticles via laser ablation," Optics and Photonics Journal, vol. 2, pp. 73-84, 2012.

[23] R. Zamiri, A. Zakaria, H. Abbastabar, M. Darroudi, M. S. Husin, and M. A. Mahdi, "Laser-fabricated castor oil-capped silver nanoparticles," International Journal of Nanomedicine, vol. 6, no. 1, pp. 565-568, 2011.

[24] M. Sheik-Bahae, A. A. Said, and E. W. van Stryland, "Highsensitivity, single-beam $\mathrm{n}_{2}$ measurements," Optics Letters, vol. 14, no. 17, pp. 955-957, 1989.

[25] M. Sheik-Bahae, A. A. Said, T.-H. Wei, D. J. Hagan, and E. W. Van Stryland, "Sensitive measurement of optical nonlinearities using a single beam," IEEE Journal of Quantum Electronics, vol. 26, no. 4, pp. 760-769, 1990.

[26] K. P. Unnikrishnan, J. Thomas, V. P. N. Nampoori, and C. P. G. Vallabhan, "Wavelength dependence of nonlinear absorption in a bis-phthalocyanine studied using the Z-scan technique," Applied Physics B: Lasers and Optics, vol. 75, no. 8, pp. 871-874, 2002.

[27] G. Tsigaridas, I. Polyzos, P. Persephonis, and V. Giannetas, "A novel approach for analyzing open Z-scan experiments," Optics Communications, vol. 266, no. 1, pp. 284-289, 2006.

[28] H. Huang and X. Yang, "Synthesis of chitosan-stabilized gold nanoparticles in the absence/presence of tripolyphosphate," Biomacromolecules, vol. 5, no. 6, pp. 2340-2346, 2004.

[29] C.-M. Shih, Y.-T. Shieh, and Y.-K. Twu, "Preparation of gold nanopowders and nanoparticles using chitosan suspensions," Carbohydrate Polymers, vol. 78, no. 2, pp. 309-315, 2009.

[30] C. F. Bohren and D. R. Huffman, Absorption and Scattering of Light by Small Particles, vol. 57, John Wiley \& Sons, Mississauga, Canada, 1940.

[31] K. Shameli, M. B. Ahmad, S. D. Jazayeri et al., "Synthesis and characterization of polyethylene glycol mediated silver nanoparticles by the green method," International Journal of Molecular Sciences, vol. 13, no. 6, pp. 6639-6650, 2012.

[32] R. Zamiri, B. Z. Azmi, H. A. Ahangar, G. Zamiri, M. S. Husin, and Z. A. Wahab, "Preparation and characterization of silver nanoparticles in natural polymers using laser ablation," Bulletin of Materials Science, vol. 35, no. 5, pp. 727-731, 2012.

[33] E. Shahriari, W. M. M. Yunus, K. Naghav, K. Behzad, and E. Saion, "Optical nonlinearity properties of Ag nanofluid measurements using a single beam Z-scan technique," Australian Journal of Basic and Applied Sciences, vol. 5, no. 3, pp. 587-591, 2011.

[34] A. G. Rad, "Single beam Z-scan measurement of nonlinear refractive index of crude oils," Journal of Modern Physics, vol. 5, no. 5, pp. 280-284, 2014.
[35] E. Shahriari, W. M. M. Yunus, and E. Saion, "Effect of particle size on nonlinear refractive index of Au nanoparticle in PVA solution," Brazilian Journal of Physics, vol. 40, no. 2, pp. 256260, 2010.

[36] E. Shahriari, W. M. Mat Yunus, K. Naghavi, and Z. A. Talib, "Effect of concentration and particle size on nonlinearity of $\mathrm{Au}$ nano-fluid prepared by $\gamma\left({ }^{60} \mathrm{Co}\right)$ radiation," Optics Communications, vol. 283, no. 9, pp. 1929-1932, 2010.

[37] E. Shahriari, W. M. Mat Yunus, K. Naghavi, and E. Bin Saion, "The optical nonlinearity of Au and Ag nanoparticle prepared by the g-radiation method," American Journal of Engineering and Applied Sciences, vol. 3, no. 2, pp. 260-264, 2010. 



\section{Hindawi}

Submit your manuscripts at

https://www.hindawi.com

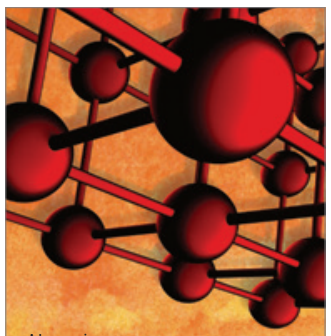

Materials Science and Engineering
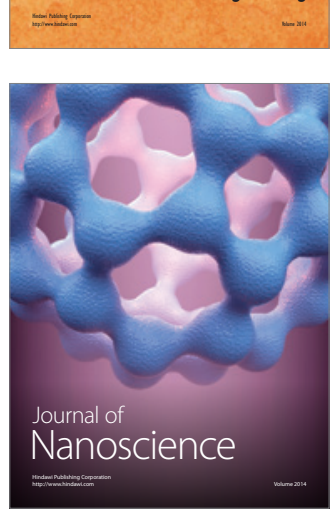
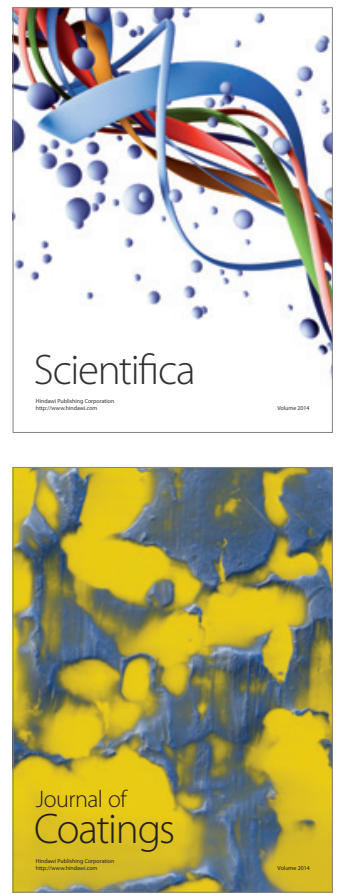
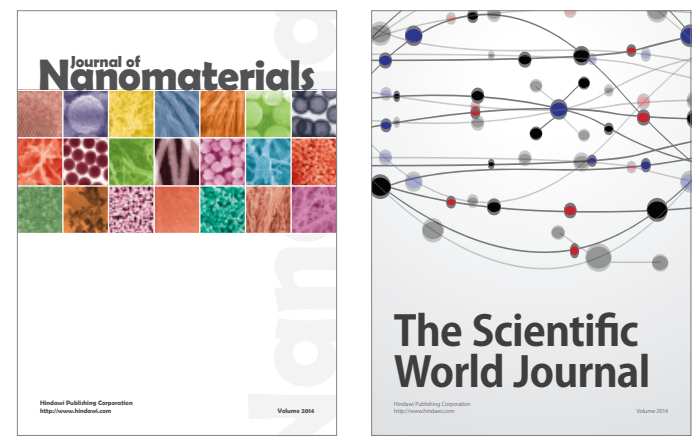

The Scientific World Journal
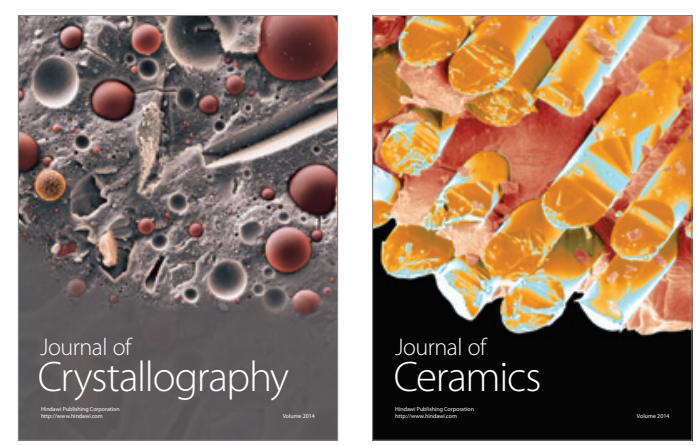
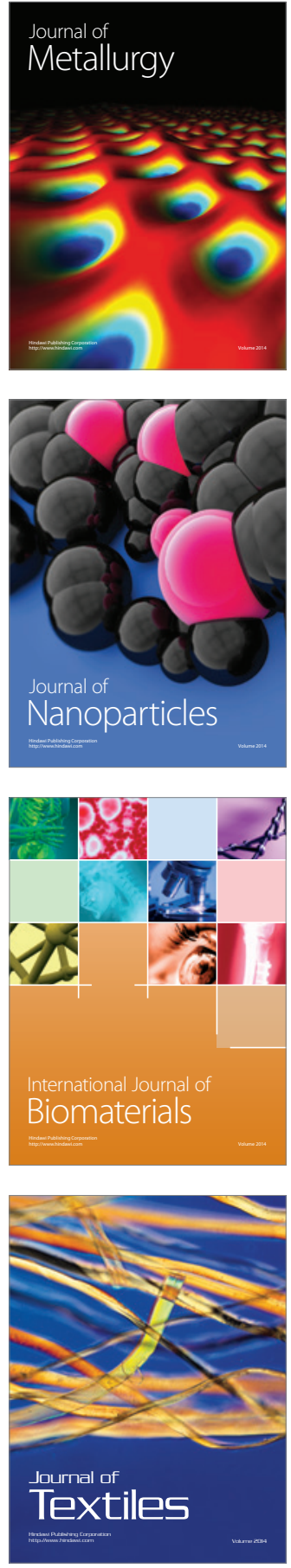